\title{
Manufacturing System Modeling and Performance Analysis of Mineral Water Production Line using ARENA Simulation
}

\author{
Dereje Geleta Oljira, Temesgen Garoma Abeya, Gutu Ofgera, Mahesh Gopal
}

\begin{abstract}
Today's scenario all manufacturing organizations are moving rapidly to adopt new process modeling, performance analysis through simulation, in order to design a new costeffective system. Organizations made several changes in their manufacturing systems to increase profit and to sustain their significance in global markets. Simulation modeling is a well accepted technique for improving process performance. In this study, the mineral water company operates the production line with less throughput, long cycle times, frequent machine failures and insufficient utilization of its resources. A simulation model is developed for the successful bottling and packaging of the production line by using Arena simulation software. The model is developed for AMWSC packaging process for returnable glass bottle Production Line. This model eliminates the bottlenecks in production line and provides optimal performance. By applying Effective Preventive Maintenance Strategy, the production line throughput is increased from $21.12 \%$ to $54.03 \%$ and the cycle time is reduced by $33.33 \%$.
\end{abstract}

Key words: System Modeling, Bottling Company, Arena Simulation, Production Line, Performance Analysis.

\section{INTRODUCTION}

Traditionally, the manufacturing system has been viewed as a sequential arrangement of functions such as design, manufacture, R\&D, marketing, finance etc [1]. Manufacturing is a transformation process in which the inputs such as raw materials, equipment, tooling and labor are converted into completed work-piece which carries some definite value in the marketplace [Daniel Kitaw,2009]. With increasing demand in production, manufacturing industries must need to increase their performance in production to increase the overall effectiveness and to face the global market, increase customer expectations. In order to fortitude today in business in this competitive market mainly depends on production time, production cost, market price and flexibility of manufacturing.

Revised Manuscript Received on May 15, 2020.

* Correspondence Author

Dereje Geleta Oljira*, Mechanical Engineering Department, College of Engineering and Technology, Wollega University, Post Box No: 395, Nekemte, Ethiopia. E-mail: singitandar@gmail.com

Dr. Temesgen Garoma Abeya, Mechanical Engineering Department, College of Engineering and Technology, Wollega University, Post Box No: 395, Nekemte, Ethiopia. E-mail: temgarom@yahoo.com

Gutu Ofera, Mechanical Engineering Department, College of Engineering and Technology, Wollega University, Post Box No: 395, Nekemte, Ethiopia. E-mail: ofgera2007@gmail.com

Dr. Mahesh Gopal, Mechanical Engineering Department, College of Engineering and Technology, Wollega University, Post Box No: 395, Nekemte, Ethiopia. E-mail: doctorgmahesh@gmail.com

(c) The Authors. Published by Blue Eyes Intelligence Engineering and Sciences Publication (BEIESP). This is an open access article under the CC BY-NC-ND license (http://creativecommons.org/licenses/by-nc-nd/4.0/)
So companies are pursuing new plan and adopt new strategy to improve their performance to reduce their costs. These things motivated researchers to research in modeling and performance evaluation through simulation in manufacturing systems. A model is defined as an abstract and simplified representation of a system which includes the most important system components and the behavior or interaction between these components and it can be used for analyze current operations and identifies problem area, Test various scenarios for improvement and Design new manufacturing systems. [3]. Modeling and simulation of flexible production systems is a field of research for many people now days. However, they all share a common aim; to search for solutions to attain higher speeds and more flexibility and thus maximize/ multiplicate manufacturing productivity [4]. Simulation software involves the design and modeling of a large variety of aspects of the production facility, including layout, equipment selection, control strategies, material handling, buffer sizing, dispatching strategies, etc. [5]. Simulation models allow to test potential changes in an existing system without disturbing it or to evaluate the design of a new system without building it and also identifies serious of bottlenecks in manufacturing systems and shows bottleneck management process. [6]. Manufacturing industries are facing a major problems like; machine setup cost and production times, Low flexibility with different models, Frequent machine failures and low maintenance strategy, high production lead time; as a result of this, low production output, low capacity utilization and bottlenecks at some stations, Problems with run speed and low line balancing efficiency [7]. All these specific problems lead to higher production cost which in turn increases the product market price [8]. The performance measures that will be used to evaluate the efficiency of different production line are throughput time which is related to: Cycle time, Machine utilization, Work in process inventory [WIP] and Waiting time [9]. The Arena modeling system from Systems Modeling Corporation is a flexible and powerful tool that allows analysts to create animated simulation models that accurately represent virtually any system [10]. These individual steps are generally called production operations, and include such processes as planning, design, procurement, production, inventory, marketing, distribution, sales and management. The key to successful manufacturing is therefore to produce constituent parts in accordance with the desired specification at the lowest cost in the shortest possible time that satisfies the customer requirement [11].

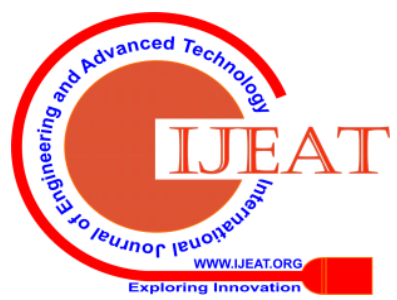


In Ethiopia's there are the top two manufacturing sectors are (i) Food and Beverage, (ii) Metal and Engineering industries, account for $51 \%$ of the sector's GDP and the food and beverage sector alone accounts $38 \%$ of the employment in the sector. [12]. The Ethiopian process industries are facing serious weaknesses and constraints hindering their productivity and competitiveness. Most of the process industries are plagued with the problem of under-capacity utilization and total resource productivity declining.

The Ethiopian process industries are facing serious weaknesses and constraints hindering their productivity and competitiveness. Most of the process industries are plagued with the problem of under-capacity utilization and total resource productivity declining. Even if the contribution of the manufacturing sector to export earnings has increased over the last few years, the contribution of Process industries for export is very marginal. Considering the unutilized capacity and unexploited potential in process a lot remains to be done [13].

Researchers show that most bottlers were producing beverages through machinery that trickle at 150 bottles per minute few decades ago. The focus of this research work is to define how the sequential nature of mineral water bottling manufacturing systems impacts the overall results with regard to throughput, cycle time, WIP inventory and cost. These are some of the critical parameters that need to be tracked for improvements in manufacturing efficiency.

\section{SYSTEM MODELLING AND PERFORMANCE ANALYSIS}

This section presents the proposed methodology that used for modeling and performance analysis of Bottling industries. In a simulation project, the ultimate use of input data is to drive the simulation model. This process involves the collection of input data, analysis of the input data, and use of the analysis of the input data in the simulation model. Furthermore, The author [14] explained about 11 steps involved in developing a simulation model, designing a simulation experiment, and performing simulation analysis which are (1) Identify the problem, (2) Formulate the problem, (3) Collect and process real system data, (4) Formulate and develop a model, (5) Validate the model, (6) Document model for future use, (7) Select appropriate experimental design, (8) Establish experimental conditions for runs, (9) Perform simulation runs, (10) Interpret and present results, and (11) Recommend further course of action. Although this is a logical ordering of steps in a simulation study, much iteration at various sub-stages may be required before the objectives of a simulation study are achieved.

\section{PROBLEM DEFINITION}

Simulation modeling and performance measure by using Arena modeling software in Ethiopian bottling industries particularly in mineral water production industries. This paper focuses on how to analyze and improve the performance of Bottling Industries

The research gap found here is that the Company only focused on material handling equipment, mainly full-pallet conveyor system, resulting in increased stretch wrapper downtime and reduced efficiency rather than overall performance analysis of production line. There is also the study conducted on how to improve the Performance of Chili Sauce Manufacturing Process using Simulation Approach. Since the packaging process is performed manually, they need to wrap each bottle of chili sauce and wait for the chili sauce to be completely cool before transferring it into the box for storage. To identify the bottleneck, the researchers used only utilization of single machine and packaging parameters here, i.e. it was not conducted on overall performance of the production line [15].

The focus of this research work is to define how the sequential nature of mineral water bottling manufacturing systems impacts the overall results with regard to throughput, cycle time, WIP inventory, utilization and cost. The case company has two major production lines [RGB and PET] with seven different products as shown in figure 1. The permissible designed working capacity of the first bottling line [RGB] is 24,000 bottles per shift, but now the average actual production is 5,069 bottles per shift. i.e. about less than one fourth of the working designed capacity. From this it can be seen that the capacity utilization of actual production with respect to the designed working capacity is only $21.12 \%$. Thus RGB line particularly operates with low performance due to: less throughput, long cycle times and insufficient utilization of its resources [machines].There are also losses such as shutdown losses, Downtime losses, performance losses and quality losses. So the performance analysis is very crucial to overcome the above mentioned problems within the company to improve its productivity.

\section{A. Arena Packaging Edition}

Arena Packaging Template is one of a family of application solution templates [ASTs] built on the Arena simulation system. It is designed specifically for performing accurate and efficient simulations of high-speed, high-volume manufacturing systems, where the processing rates take place at hundreds, even thousands, of entities per minute. The Packaging template contains a collection of objects or modules. Each module defines the logic, data, animation, and/or statistics collection for a particular element in a model [e.g., machines, conveyors, operators, Links, etc.].

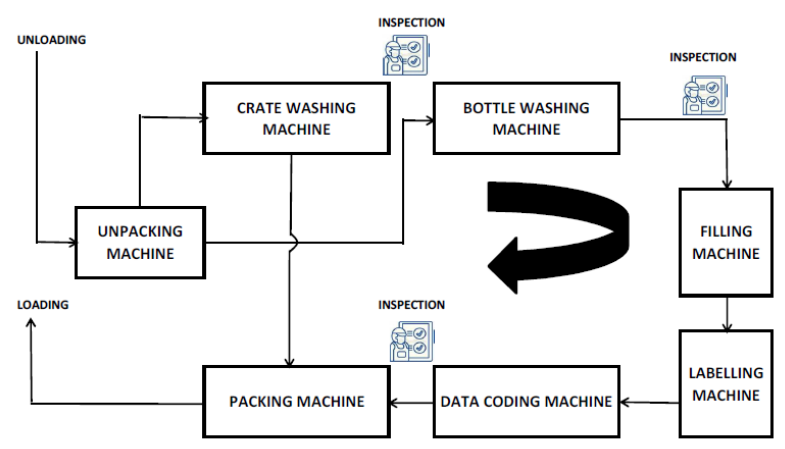

Fig.1. Returnable Glass Bottle [RGB] Production Line Description

Published By:

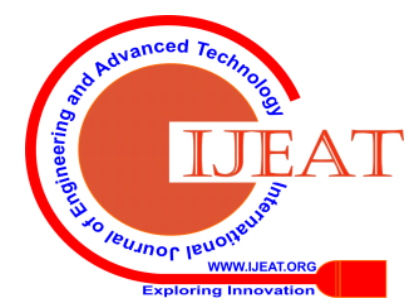




\section{B. Materials and Methods}

Activity identification in the production lines, process mapping to understand how the product [entities] are actually moving, processes time collection and analyzing using Built in Arena input analyzer, simulation model development and identification of replication numbers were the methodologies used. The study was conducted by considering different materials and methods to achieve the goal of this study. The literature reviews and arena software applications were utilized to come up with good solution. By the data collection, a simulation model will be designed to identify what kind of improvement that could be made in the production line.

This paper covers two main stages; the data collection and the simulation model for the production line of RGB line. The data collection stage is the first step in the modeling methodology, and should be well planned in targeting key data that would reflect the simulation model objectives. Then the simulation model is developed. In the model development, the kinds of data that are to be collected are: Actual Resource processing time and Observation and machine parameters i.e. Nominal Run Speed, Capacity, Length, width, the loss data such as; Lost Units after Failure, Lost Units after Stop and Production Based Loss [\%],Reliability data like expected uptime, reliability over a time span and individual failure stream and cost data; Cost/hr, Cost/Good Units, Cost/Lost Units. For the line almost during the previous one year [since January 1, 2018 data] average actual production for RGB is 5,069 bottles per shift.

\section{Modeling Framework}

There are five steps modeling methodology for developing those simulation models in Arena Packaging Edition. The methodology provides a framework for learning how models are built and analyzed using the packaging template.

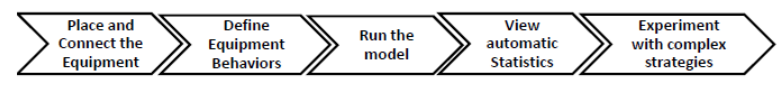

Fig.2. The five - Steps of methodology in Arena Packaging Edition

Simulation modeling for performance measure by using Arena modeling software is relatively new field and one that were not most probably applicable in Ethiopian bottling industries particularly in mineral water production industries. To analyze and improve the performance of AMWSC RGB Production line, the simulation tool used were Rockwell Arena Simulation Software 14.00 version [Professional Edition].

\section{Data Interpretation using the Input Analyzer Tool}

The input analyzer and expert fit results provide the probability distribution type and the value of the distribution ready to be entered in the Arena modules dialogue. The square error is provided with the best fit result which should be the least square error for the other probability distribution for this particular set of data points. The Input Analyzer provides the data summary and histogram chart for the set of data provided and the Expert Fit tools built in Arena were used to convert the data into probability distributions to be used in the simulation model.

\section{MODEL DEVELOPMENT}

\section{A. Formulation and Developing the Model}

Areas taken for the modeling and simulation were Packaging section. The modeled system under consideration is a discrete parts manufacturing system. Component parts used as raw materials for the manufactured product such as Glass Empty Bottle and Crowning corks. RGB Empty Glass Bottle was taken as an entity for simulation modeling. The working hour for the factory is divided into three shifts. This is the planned working schedule of the factory and the production time of the line of the three shifts totally 24hours. The line starts at 6:00Am [morning] and ends production at 6:00Am [morning] without any break.

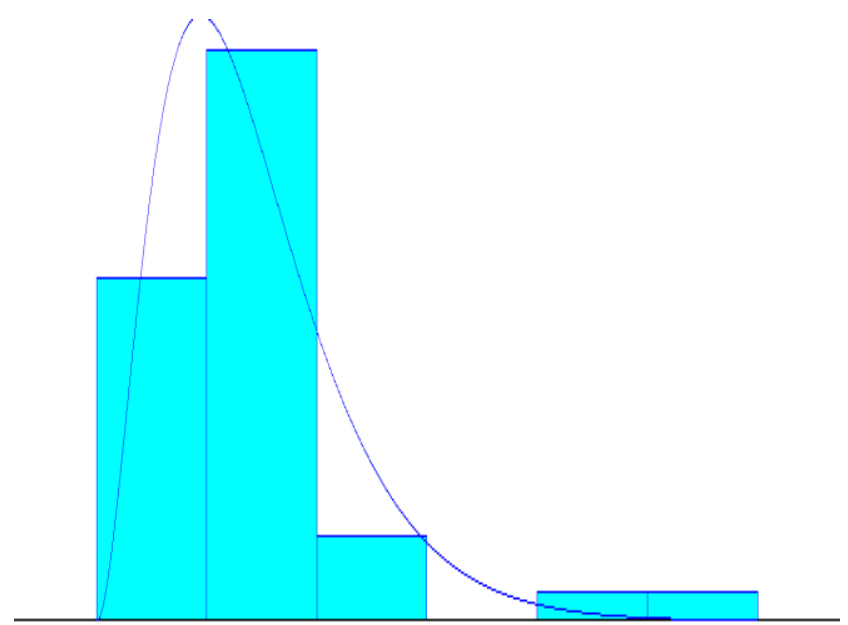

Fig.3. The actual data distribution and the fitted distribution for filling Machine'

\begin{tabular}{|c|c|}
\hline Distribution Summary & $\begin{array}{c}\text { Kolmogorov: Smirnov } \\
\text { Test } \\
\end{array}$ \\
\hline $\begin{array}{l}\text { Distribution: Erlang } \\
\text { Expression : ERLA [0, 0] } \\
\text { Square Error:0.019535 }\end{array}$ & $\begin{array}{l}\text { Test Statistic }=0.093 \\
\text { Corresponding } \quad \text { p-value }> \\
0.15\end{array}$ \\
\hline Chi Square Test & Data Summary \\
\hline $\begin{array}{l}\text { Number of intervals }=3 \\
\text { Degrees of freedom }=0 \\
\text { Test Statistic } \quad=3.19 \\
\text { Corresponding p-value }< \\
0.005\end{array}$ & $\begin{array}{lr}\text { Number of Data Points }=37 \\
\text { Min Data Value } & =0.1 \\
\text { Max Data Value } & =3.17 \\
\text { Sample Mean } & =0.82 \\
\text { Sample Std Dev } & =0.571\end{array}$ \\
\hline
\end{tabular}

\section{B. Modeling Assumptions}

The model for one shifts are modeled and analyzed. In the study only RGB Production line is selected.

(1) PET Production Line is almost modern, automated and smoother than RGB line, so the researcher mainly focused on RGB line. [2]

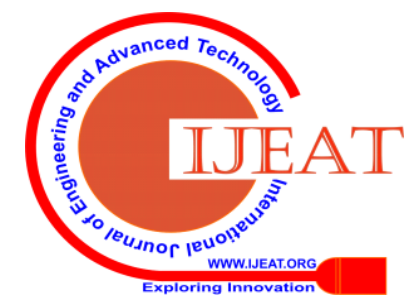


The number of empty glass bottles in is equal to the filled glass bottles out for RGB line. [3]

For the modeling, machines such as; Date Coding Machine, Capping Machine, Crate Washing Machine and Blender Machine were neglected for RGB line; this is because of those machines made a minor change effects on production losses of the line. [4] The Modeling for RGB line occupies from Unpacking Machine to Packing Machine. [5] The mineral water, which is to be filled in the bottle by filling machine is assumed as it is supplied from the storage tank and already cleaned and treated finally mixed with $\mathrm{CO}_{2}$ in blender tank and directly pumped to the filler tank.

\section{SIMULATION MODEL RESULTS AND ANALYSIS}

\section{A. Model Verification and Validation}

The credibility of output of any simulation run largely depends on the model's ability to mimic reality. A simulation model should be free of any programming bugs [verification] and should also reflect the "as-is" situation or perform in the way it is expected [validation]. One should be able to draw valid and acceptable conclusions from results by running the simulation models. Verification is the process to check that the model is running according to the modeling assumptions and answers the question: how we built the model right? As well as the correctness of the model. Validation is the

RGB Prowuction Lime
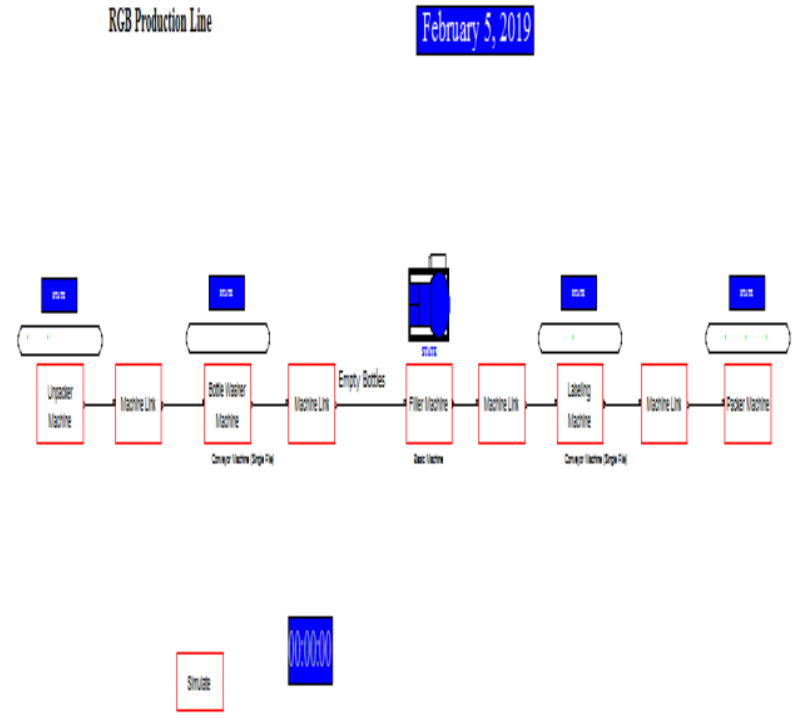

Fig.4. Simulation model developed

process to ensure that the behavior of the model matches the behavior of the real system. The model is built based on the existing configuration of the system so that its overall appearance resembles to the actual system. When we compare the throughput of the actual production rates and the simulation model run results; it is observed that the actual daily production ranges from 14,000-18,000 bottles/day. The total daily production of the virtual model is 14,538 bottles per day. It is found that the production rate for the virtual model approximates the rates for the factory.
Hence, the simulation model is validated. Modifications were done on the existing model by manipulating the model parameters, and observing the run results of the modified model.

\section{B. Multi Run Statistical Data Analysis}

The number of runs [replications] is 6 instead of one so that the system will reach the steady state. The length of replication is defined for 24 hours each [and total of one week production duration i.e. 6 working days]. Initialization to the system and statistics is needed since the work recontinues on day after day. In this type of production, models must be built on a replication length basis. By this marking, simulation will result in above 10 statistically independent and identical replications [IIR] and reports, each starting with an empty system at a time 0 and each will finish when the manufacturing process will be done [Replication Length $=1440$ minutes]. The base time unit is selected as minutes. From the model of existing system output summary for 6 Replications, the Output [total good units produced] by this modeled station is 4,846 bottles /shift.

When a utilization of machines is taken into account it is seen that the Unpacker machine is the least utilized machines as well as Filling Machine and Bottle Washing Machines are also other less utilized machines.

From the available maintenance data, machine like: Filler machine and Labeling machine Use Expected up Time to define their reliability; Unpacker machine and packer machine Use Individual failure streams and washing machine Use Reliability over a Time Span.

\section{Proposed Model Development}

The proposed model is built based on the existing system model. To build the proposed model different analysis and decision-making are used on the existing model. The first type of analysis used is bottleneck analysis. During this analysis, some bottlenecks are identified and eliminated. The bottlenecks were identified based on factors like machine utilization and machine performance.

\section{Identifying and eliminating the System Bottlenecks}

To examine improvements in the system, simulation strategies need to be done. Changes can be made on the model parameters and the effects can be monitored through the run results. One of the main interests for improvement is to reduce the cycle time or processing time of the line. The actual system is highly interrupted at two points/ stations: one is at bottle washing machine and the second is at filling machine [during filling and capping time]. The main bottlenecks to the system are bottle washing machine, filling machine and Unpacker Machine. Since, the simulation model could justify improvements, we need to know the new parameters that could enter into the proposed or the modified model, so that it could be entered and examined by the run results. In actual setting, the following parameters are critical in any intended process improvements.

Cycle time and Process time are the two main parameters.

Published By:

Blue Eyes Intelligence Engineering

Retrieval Number: D8033049420/2020 CBEIESP

DOI: 10.35940/ijeat.D8033.069520

Journal Website: www.ijeat.org

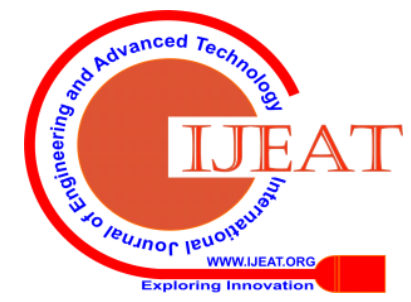


Reducing any or both will reflect substantially on improvement.

Bottlenecks due to machine failures are reflections of the excessive time lost within the processing time of the station and should be eliminated.

In order to achieve substantial improvement on the productivity, we need to apply the following methods: First new processing methods could be used to improve the process [throughput] and make it time effective. Having this goals done we can move to another level of improvement that is to applying a most critical preventive maintenance strategies or techniques. Line balancing of processes eliminates bottlenecks [i.e. blockage and starvation]. Because line balancing will get all stations to have approximately the same process time so no station would wait for another since they start and finish during a fixed time. RGB production process takes for at least 1 hour in the production line to complete its process. But its cycle time can be reduced for about 40 minutes if the production system is continuous and fully automated.

\section{E. Proposed Scenarios}

The constructed model can be subjected to various proposals, strategies and "what-if" scenarios, which may be far too risky and expensive to implement in a real life. The virtual system in the model responds just like the real operation would - revealing the impact of proposed change on your throughput, cycle time, and profit margins. With this, we gain the confidence to select and implement only the strategies that have been proven to work, eliminating the risk of improper implementations. The final result will be optimal line performance and maximized operating efficiency. Processing times, system total cost, total product output and utilization of each machine were the main concerns in this production process, hence, keeping this in mind, three scenarios including existing scenario are created. A separate model is constructed for each scenario.

\section{F. Scenario 1: Modifying the Existing Line}

By modifying the existing resource parameters like improving the station working conditions, nominal velocity, capacity and worker efficiency on the station, it is possible to improve the performance to certain extent. We can reach to an output of 9,696 bottles per shift. Increasing production rate using the same resource under the same costs is one of the efficient ways to keep the manufactured product competitive. The modified model shows that there is possibility of increasing the throughput of the bottled mineral water production up to $50.02 \%$.

\section{G. Scenario 2: Applying Effective Preventive Maintenance Strategy}

Preventive Maintenance is a critical part of any production process to ensure maximized production and minimized unplanned downtime. Downtime will be more predictable if we could use preventive maintenance. As the downtime becoming a controllable variable, system uncertainty will be lowered and production can be maximized through the reallocation of resources. The current production system of Ambo Mineral Water Share Company RGB Production line has unsatisfactory overall availability due to downtime caused by some machine/component failures.
Here some of the data like station reliability and maintainability are analyzed from historical data by assessing station's mean-time-to-failure [MTTF] and Meantime-to-repair [MTTR]. The availability of the station is based on the actual time and total time [availability = actual production/ total time]. The three options found in Arena Package Template for defining random downtimes are: Using Expected Uptime, Using Reliability over a Time Span, and Using Individual Failure Streams. By applying preventive maintenance strategy and utilized skilled maintenance crew we can improve the three stated values and hence the downtime of the overall system. By doing so, we can reach to an output value of 10,542 bottles per shift. So due to this fact the modified model shows that there is possibility of increasing the throughput of the bottled mineral water production up to $54.03 \%$.

Table - I. Some modified parameters of the line

\begin{tabular}{|c|c|c|c|c|c|c|c|}
\hline \multirow{2}{*}{$\begin{array}{l}\mathrm{S} \\
1 \\
\dot{\mathrm{N}} \\
\mathrm{O}\end{array}$} & \multirow[t]{2}{*}{$\begin{array}{l}\text { Machine } \\
\text { Type }\end{array}$} & \multicolumn{2}{|c|}{$\begin{array}{l}\text { Machine } \\
\text { Capacity }\end{array}$} & \multicolumn{2}{|c|}{$\begin{array}{c}\text { Existing } \\
\text { Model }\end{array}$} & \multicolumn{2}{|c|}{ Scenario - 1} \\
\hline & & $\begin{array}{l}\text { Nomi } \\
\text { nal } \\
\text { Run } \\
\text { speed } \\
\text { [units/ } \\
\text { min] }\end{array}$ & $\begin{array}{l}\text { Capa } \\
\text { city } \\
\text { [bottl } \\
\text { es/cy } \\
\text { cle] }\end{array}$ & $\begin{array}{l}\text { Nomi } \\
\text { nal } \\
\text { Run } \\
\text { speed } \\
\text { [units/ } \\
\text { min] }\end{array}$ & $\begin{array}{l}\text { Capa } \\
\text { city } \\
\text { [bottl } \\
\text { es/cy } \\
\text { cle] }\end{array}$ & $\begin{array}{l}\text { Nomi } \\
\text { nal } \\
\text { Run } \\
\text { speed } \\
\text { [Units } \\
\text { /min] }\end{array}$ & $\begin{array}{l}\text { Ca } \\
\text { pa } \\
\text { cit } \\
y \\
\text { [b } \\
\text { ott } \\
\text { les } \\
\text { /cy } \\
\text { cle } \\
\text { J }\end{array}$ \\
\hline 1 & $\begin{array}{l}\text { Bottle } \\
\text { Washing } \\
\text { Machine }\end{array}$ & 680 & 620 & 390 & 534 & 530 & $\begin{array}{c}53 \\
4\end{array}$ \\
\hline 2 & $\begin{array}{l}\text { Filling } \\
\text { Machine }\end{array}$ & 540 & 450 & 377 & 400 & 430 & $\begin{array}{c}40 \\
0\end{array}$ \\
\hline 3 & $\begin{array}{l}\text { Unpacki } \\
\text { ng } \\
\text { Machine }\end{array}$ & 850 & 530 & 800 & 500 & 550 & $\begin{array}{c}50 \\
0\end{array}$ \\
\hline 4 & $\begin{array}{l}\text { Labeling } \\
\text { Machine }\end{array}$ & 150 & 540 & 100 & 100 & 200 & $\begin{array}{c}45 \\
0\end{array}$ \\
\hline 5 & $\begin{array}{l}\text { Packing } \\
\text { Machine }\end{array}$ & 850 & 630 & 800 & 500 & 500 & $\begin{array}{c}55 \\
0\end{array}$ \\
\hline
\end{tabular}

\section{H. Comparison of Alternative Scenarios}

From the comparison of scenarios it is clear that Scenario 2 - Applying Effective Preventive Maintenance Strategy is the best of all. This is due to the maximum throughput obtained, highly utilized machine, and reduced wastage and improves cycle time. In addition the performance of each resource in this scenario is higher than others as shown table above. Cost justifications by comparing the existing system with modified ones

\section{CONCLUSION}

MSMPA using Arena Simulation software is one of the promising tools employed for assessing performance and then taking the necessary measures for improvements of existing deficiencies.

Published By:

Blue Eyes Intelligence Engineering

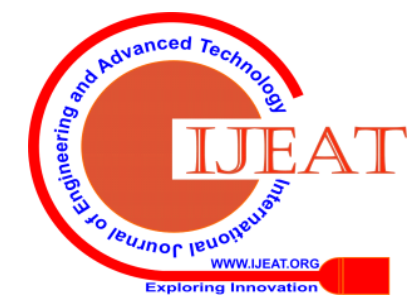


Arena simulation modeling of RGB Production Line is used for better understanding and modification of the manufacturing system performance and behaviors. After analyzing the simulation result of the three scenarios, the Scenario 2: Effective Preventive Maintenance Strategy is the best option. By implementing the strategy, the output of the RGB production line from 21.12\% [existing capacity utilization] to $54.03 \%$ and cuts cycle time by $33.33 \%$ with the minimum possible capital investment and reduces the costs of corrective and breakdown maintenance. MSMPA using Arena Simulation software is one of the promising tools employed for assessing performance and then taking the necessary measures for improvements of existing deficiencies.

\section{ACKNOWLEDGEMENTS}

The authors thank the Ambo Mineral Water Share Company [AMWSC] the support given by the managements for the successful completion.

\section{REFERENCES}

1. N. Viswanadham, Y. Narahari, and N. R. S. Raghavan, "Design/Analysis of Manufacturing Systems: A Business Process Approach," Group Technology and Cellular Manufacturing, pp 221-238, 1998.

2. Daniel Kitaw, "Industrial Management and Engineering Economy," Addis Ababa, Ethiopia: AAU press,2009.

3. F.Chance, J.Robinson, and J. Fowler, " Supporting manufacturing with simulation: model design, development, and deployment", Proceedings of the 1996 Winter Simulation Conference, San Diego, CA, pp. 18.1996.

4. Mohamed Boualem, Mouloud Cherfaoui, Amina Angelika Bouchentouf, and Djamil Aïssani, "Modeling, Simulation and Performance Analysis of a Flexible Production System," European Journal of Pure and Applied Mathematics, Vol. 8, No. 1, 26-49, 2015.

5. Pavol Semanco, and David Marton, "Simulation Tools Evaluation using Theoretical Manufacturing Model," Acta Polytechnica Hungarica, Vol. 10, No. 2, 2013.

6. C. E. Betterton, and S. J. Silver, "Detecting bottlenecks in serial production lines-a focus on interdeparture time variance," International Journal of Production Research, 50[15], 4158-4174, 2012.

7. Desalegn Hailemariam, "Mixed Model Assembly Line Balancing Using Simulation Techniques," Addis Ababa University, Sep. 2009.

8. J. Heizer and B. Render, "Production and operations management," 2nd ed. Massachusetts: Allyn and Bacon, pp. 229-243, 1998.

9. Abebayehu Seifu, "Simulation and Performance Analysis of Manufacturing Systems Using Deterministic and Stochastic Petri Nets," Addis Ababa, Ethiopia: Addis Ababa University, 2007.

10. J.Banks, J. S.Carson, B. L.Nelson, and D. M. Nicol,. Discrete-Event System Simulation 4th ed. Upper Saddle River, New Jersey: PrenticeHall Incorporated, 2004.

11. P. Groover, Automation, Production Systems and Computer-Integrated manufacturing, 2nd Edition, Pearson Education, Delhi, 2000.

12. A Survey of Ethiopian Manufacturing Sector, Manufacturing Survey Analysis. Addis Ababa, Ethiopia: Addis Ababa Chamber of Commerce and Sectoral Associations [AACCSA], 2014.

13. http://www.selamta.net/economy, Ethiopian Economy, 2018.

14. Anu Maria, "Introduction to Modeling and Simulation," Proceedings of the 1997 Winter Simulation Conference, San Diego, CA, pp. 7-15. 1997.

15. Y.Choong, H.Siti, and M.Ireen, MALAYSIA, School of Mathematical Sciences, Faculty of Science and Technology University Kebangsaan Malaysia, 2005.

\section{AUTHORS PROFILE}

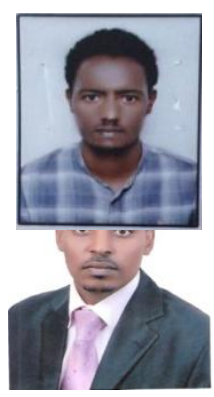

Dereje Geleta Oljira, graduated B.Sc. in Mechanical Engineering, graduated M.Sc in Mechanical Engineering specialized in Industrial Engineering in July 2018 from Wollega University, Nekemte, Ethiopia. He has 6 years of teaching experience. His areas of interest are Applied Operations Research and Optimization, Production Operations Management, Modeling and Simulation of Industrial and Production Systems, and Industrial Project Management.

Dr. Temesgen Garoma graduated B.Sc. in Mechanical Engineering (Automotive Technology) in July 1999 from Adama Science and Technology University, Ethiopia; graduated M.Sc in Mechanical Engineering specialized in Industrial Management in July 2004 from Addis Ababa University. He completed his $\mathrm{PhD}$ at Addis Ababa University in 2012. He worked in at Arbaminch University as lecturer for about five years and Joined Wollega University, Nekemte, Ethiopia in 2007. Furthermore, he served Ethiopian Universities as Research and Technology Innovation Director, Dean for college of Engineering and Technology, Vice president for Administration and A/President positions. His research area mainly focuses on: Supply Chain Design, Value Chain Analysis, Applied Operations Research and Optimization, Production Operations Management, Modeling and Simulation of Industrial and Production Systems, and Industrial Project Management.

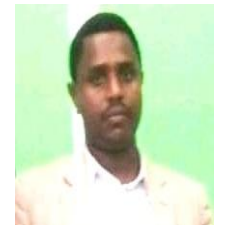

Gutu Ofgera, graduated B.Sc. in Mechanical Engineering in 2003 from Bahir Dar University, graduated M.Sc in Mechanical Engineering specialized in Industrial Engineering in 2007, from Addis Ababa University. He worked 8 years in Bahir dar university and then joined in Wollega university and still working here for 10 years. He has total 18 years of teaching experience. His areas of interest are Optimization, Production Operations Management, Modeling and Simulation of Industrial and Production Systems, and Industrial Project Management.

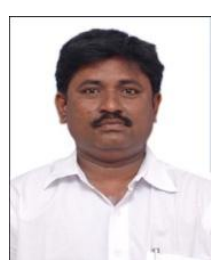

Dr. Mahesh Gopal graduated his Bachelor degree in department of Mechanical Engineering from P.S.N.A College of Engineering and Technology, Kamaraj University, Madurai, India in 1998, completed Master of Engineering degree from Thiagarajar College of Engineering, Kamaraj University, Madurai, India in 2003, Completed PhD in Anna University, Chennai, India in 2013. He has 20 years of academic experience at various capacities. Currently he is working as a faculty in the Department of Mechanical Engineering, Wollega University, Nekemte, Ethiopia. His areas of interest are Production Engineering, Optimization techniques, Vibration, TPM etc.

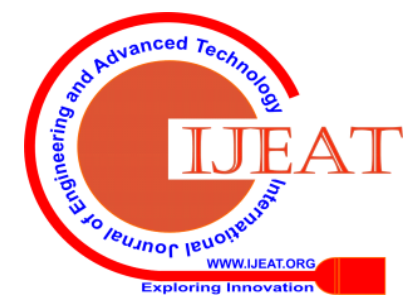

